\title{
The Sensitivity of the Greenland-Scotland Ridge Overflow to Forcing Changes
}

\author{
ARne Biastoch* \\ Scripps Institution of Oceanography, La Jolla, California \\ ROLF H. KÄSE \\ Institut für Meereskunde, Kiel, Germany \\ DetLef B. StAMmer \\ Scripps Institution of Oceanography, La Jolla, California
}

(Manuscript received 11 February 2002, in final form 7 April 2003)

ABSTRACT

\begin{abstract}
Processes that influence the volume and heat transport across the Greenland-Scotland Ridge system are investigated in a numerical model with $16^{\circ}$ horizontal resolution. The focus is on the sensitivity of cross-ridge transports and the reaction of the subpolar North Atlantic Ocean circulation to changes in wind stress and buoyancy forcing on seasonal to interannual timescales. A general relation between changes in wind stress or cross-ridge density contrasts and the overturning transport of Greenland-Iceland-Norwegian Seas source water is established from a series of idealized experiments. The relation is used subsequently to interpret changes in an experiment over the years 1992-97 with realistic forcing. On seasonal and interannual timescales there is a clear correlation between heat flux and wind stress curl variability. The realistic model suggests a steady decrease in the strength of the cyclonic subpolar gyre of the North Atlantic with a corresponding decrease in heat transport during the 1990s.
\end{abstract}

\section{Introduction}

The role of the Greenland-Iceland-Norwegian (GIN) Seas in North Atlantic Deep Water (NADW) formation and in determining our present and future climate seems to be widely accepted (Dickson and Brown 1994). However, a detailed understanding of adjustment processes of the flow over the Greenland-Scotland Ridge (GSR) to changing forcing conditions over the GIN Seas and its impact on the Atlantic Ocean and global circulation still has to be established. In particular, the interaction between the changing GIN Seas and the North Atlantic flow fields has to be understood. This includes an understanding of the relative importance of wind forcing as compared with buoyancy fluxes and the relative importance of atmospheric fluctuations poleward or equatorward of the GSR.

The areas of the subpolar North Atlantic are exposed to high surface winds. Wind stress curls calculated from satellite data reveal very high values west of Greenland

* Current affiliation: Institut für Meereskunde, Kiel, Germany.

Corresponding author address: Dr. Arne Biastoch, Institut für Meereskunde, Düsternbrooker Weg 20, 24105 Kiel, Germany.

E-mail: abiastoch@ifm.uni-kiel.de
(Milliff and Morzel 2001), driving a cyclonic barotropic circulation around Iceland that links the GIN Seas and the subpolar North Atlantic. Such extreme values that are also seen in the climatology used here (Stammer et al. 2004, manuscript submitted to J. Climate) are not constant in time but vary on seasonal, interannual, and longer timescales (see also Fig. 11). Late winter values are 2 times those in the summer and interannual variations are of similar amplitudes.

Especially the upper layer in the Norwegian Sea has been attributed to variations in the surface pressure field of the North Atlantic (Blindheim et al. 2000). The current transporting these anomalies [e.g., of North Atlantic Oscillation (NAO) type] is the Norwegian Atlantic Current entering across the eastern part of the GSR.

From numerical simulations it has emerged that the overflow of dense GIN Seas water over the GSR has a significant effect on the meridional overturning circulation (MOC) of the North Atlantic (Willebrand et al. 2001). However, the timescales of overflow changes are not well established, nor are those of the reaction of the flow field. Recent measurements (Girton et al. 2001) in the northern branch of the overflow through the Denmark Strait revealed no significant change in transports as compared with measurements from more than a decade ago (Ross 1984). On the other hand, there are 
indications that the southern branch through the Faeroe Bank Channel (FBC) decreased in its strength over the last $50 \mathrm{yr}$ (Hansen et al. 2001). The authors interpret recent direct current measurements in terms of hydraulic control theory. Applying those relations to historic data of the reservoir height of GIN Seas water the authors inferred that the long-term throughflow is subject to a significant trend to lower overflow volumes.

Similar long term transport estimates do not exist for the Denmark Strait. However, the importance of a hydraulic control mechanism in the Denmark Strait has been established in numerical simulations (Käse and Oschlies 2000) and measurements (Käse et al. 2003). However, in contrast to the FBC, the Denmark Strait can be considered to be a "wide channel" (i.e., a width much larger than the Rossby radius), and therefore different hydraulic laws apply. Jónsson (1999) suggests that the main contribution to the Denmark Strait Overflow Water (DSOW) comes from the Iceland Sea with a persistent direct path to the Denmark Strait bypassing the East Greenland Current. This is supported by longterm measurements north of Iceland and leaves little room for strong variability in this component of the DSOW. It is therefore more likely that variations in and farther downstream of the sill are related to mixing with East Greenland Current and Irminger Sea water.

In a recent paper (Käse et al. 2001) we have shown that a regional model of the North Atlantic subpolar gyre is able to simulate realistic circulation patterns that are connected to the GSR overflow on timescales up to several years. The simple model accounts for the mean density difference between the two basins north and south of the GSR and surface forcing and simulated predominant pathways of water masses and heat. It is the purpose of this paper to investigate the sensitivity of mass and heat transports in such a model to changes in wind stress and cross-ridge buoyancy contrasts.

From the idealized setup we can expect responses on two different timescales: First, a fast response on changes in the surface forcing; and second, a slower one on changes of properties in the reservoir north of the sills. While the response of the flow field to changing reservoir properties has a timescale of several years to decades, the response of the flow field to changing winds and density contrasts is relatively fast. Therefore, instead of driving a model to near equilibrium over many decades to changes in surface heat and wind changes, we take advantage of the fact that the spinup time in the subpolar gyre is rather short. The barotropic nature and the fast propagation of anomalies along the topography leads to statistically stationary mass and heat transports across the GSR in our model after a few months. We therefore can determine dependencies between wind forcing and flow response with relatively low computational costs. (In contrast, the subtropical gyre spinup time is significantly longer and is determined by the propagation time of baroclinic Rossby waves across the whole basin.)
In the following, we will first describe the idealized model setup used in this sensitivity study (section 2). Section 3 describes these results and establishes a relationship between total Denmark Strait throughflow and heat transport across the GSR. This relationship is tested against the results from a more realistic setup in section 4 and is discussed in the conclusions.

\section{The model}

Our numerical experiments are based on the Massachusetts Institute of Technology (MIT) ocean model (Marshall et al. 1997a,b), which is a primitive equation model with $z$ coordinates in the vertical. The model domain covers the subpolar North Atlantic and parts of the GIN Seas between $40^{\circ}$ and $75^{\circ} \mathrm{N}$ and between $70^{\circ} \mathrm{W}$ and $5^{\circ} \mathrm{E}$. Our setup has a horizontal resolution of $1 / 6^{\circ} \times$ $16^{\circ}$, which over the Denmark Strait results in grid sizes of $9.5 \mathrm{~km} \times 18 \mathrm{~km}$ in zonal and meridional direction, respectively. In the vertical, the model has 30 levels with a resolution ranging from $\Delta z=10 \mathrm{~m}$ near the surface to $875 \mathrm{~m}$ close to $5000-\mathrm{m}$ depth. Because all lateral boundaries are closed (no normal flow), the largescale overturning due to the North Atlantic Current (NAC) warm branch (that in reality enters the domain from the south) and its regional impact is absent in our simulation.

The model topography was obtained on the model grid from the National Geophysical Data Center (NGDC) 5 arc-min dataset through bilinear interpolation with no extra smoothing applied (Fig. 1a). Some additional tuning was required to assure that important islands are represented (e.g., Jan Mayen). In contrast to the traditional vertical discretization of $z$-level models, the MIT model allows partially filled cells, thus providing a more realistic representation of the bottom topography and bottom slopes (Adcroft et al. 1997). Käse et al. (2001) have demonstrated that the correct representation of topographic slopes is fundamental for a realistic simulation of the flow field and its variations in the subpolar North Atlantic.

A series of idealized model runs was performed that differ only in terms of wind forcing and initial buoyancy contrast (Table 1). The standard wind forcing consists of a 7-yr time mean that was estimated through a global ocean state estimation procedure for the years 1992-97. As described by Stammer et al. (2002, 2003), the estimated fluxes (later referred to as ECCO forcing) are those that are consistent with this model (on a $2^{\circ}$ global grid) and with a variety of ocean data. To account for a typical range of wind stress variability for this area (e.g., Spall and Pickart 2003), these wind fields were multiplied by a factor of 2-4 (expts $2 \times$ WIND and 4 $\times$ WIND). While doubling the strength of the wind forcing is consistent with observed wind variation, a factor of 4 can be considered to be an extreme case that is used here only to illustrate a clear scaling relation between wind forcing and transports. 

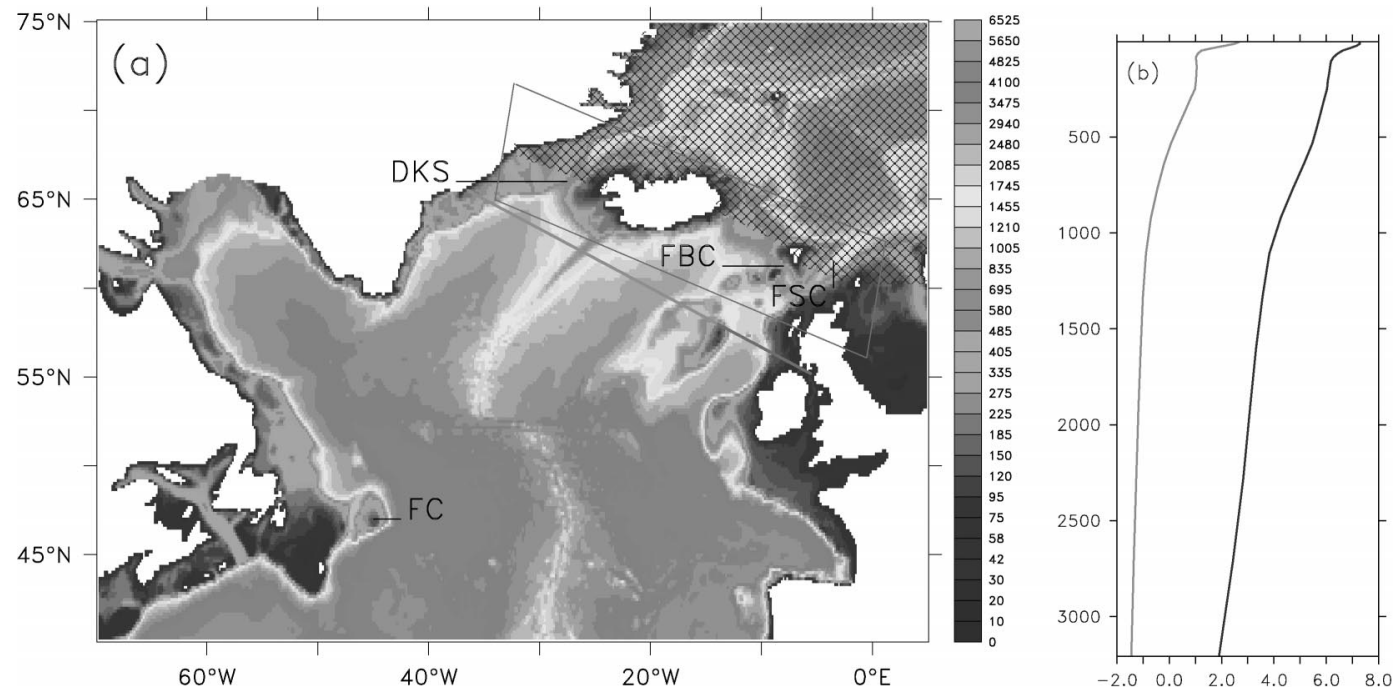

FIG. 1. (a) Topography of the subpolar model. Pixels indicate horizontal resolution, and the discretization of the depth axis (m) is shown by the grayscale. The hatching represents the GIN Seas. Special topographic features that are referenced in the text are also shown: Flemish Cap (FC), Denmark Strait (DKS), Faeroe Bank Channel (FBC), and Faeroe-Shetland Channel (FSC). The box indicates the area of Figs. 2 and 9. The diagonal line indicates the section shown in Fig. 5. (b) Initial temperature profiles of the idealized model versions: GIN Seas (gray) and subpolar North Atlantic (black).

The initial stratification was determined by averaging the annual mean Levitus and Boyer (1994) potential temperature $\theta$ field horizontally over the two basins north and south of the GSR (Fig. 1b). The contrast across the GSR was modified in some experiments by multiplying the southern profile by a factor of 1.5 (expt $1.5 \times$ TEMP) or 2 (expt $2 \times$ TEMP). This range is larger than can be inferred from observations but is used to demonstrate the insensitivity of the barotropic transport through the Denmark Strait to density forcing.

In all of our idealized runs, density was calculated from temperature alone using a least squares-fitted temperature-density relation (based on observations) of $\sigma$ $=27.95-0.09 \theta$. This enabled us to use salinity as an independent "GIN Seas tracer" for water originally denser than $\sigma=28.0$ to trace the spreading of cold overflow water into the subpolar gyre. The GIN Seas tracer was initialized by a value of 1 north of the sills and below $100 \mathrm{~m}$. No relaxation toward a climatology was accomplished along the artificially closed boundaries to allow closing the heat budget in the model domain.
Horizontal subgrid-scale physics were parameterized by a biharmonic operator with values scaled by $\cos ^{3}(\varphi)$ (where $\varphi$ is the geographical latitude). At $60^{\circ} \mathrm{N}$ this corresponds to $6.25 \times 10^{9} \mathrm{~m}^{4} \mathrm{~s}^{-1}$ for viscosity and 1.25 $\times 10^{9} \mathrm{~m}^{4} \mathrm{~s}^{-1}$ for diffusion. In the vertical, a constant Laplacian is used with a value of $1 \times 10^{-4} \mathrm{~m}^{2} \mathrm{~s}^{-1}$ for the viscosity and $3 \times 10^{-5} \mathrm{~m}^{2} \mathrm{~s}^{-1}$ for the diffusion. Gravitational instabilities are removed by an implicit treatment of the vertical mixing where high mixing values are used for unstable stratified water columns. To ensure a positive definite advection of tracers, a fluxcorrected third-order scheme was used.

\section{Result of the sensitivity experiments}

\section{a. Testing results}

The WIND experiment will be used as a reference case for pathways of the warm water and deep water flows. Hansen and Østerhus (2000) showed in their Fig. 5 that the warm water path into the northern basin consists of two branches, the Faeroe Current west and the

TABLE 1. Summary of idealized experiments.

\begin{tabular}{llll}
\hline \hline & & \multicolumn{1}{c}{ Forcing } & \multicolumn{1}{c}{ Ititialization } \\
\hline Wind & WIND & Wind & Two profiles \\
& NOWIND & No & Two profiles \\
& $2 \times$ WIND & Doubled wind & Two profiles \\
& $4 \times$ WIND & Quadrupled wind & Two profiles \\
Temperature & $1.5 \times$ TEMP & Wind & Two profiles \\
& $2 \times$ TEMP & Wind & Subpolar profile $\times 1.5$ \\
& & & Two profiles \\
& & & Subpolar profile $\times 2$ \\
\hline
\end{tabular}



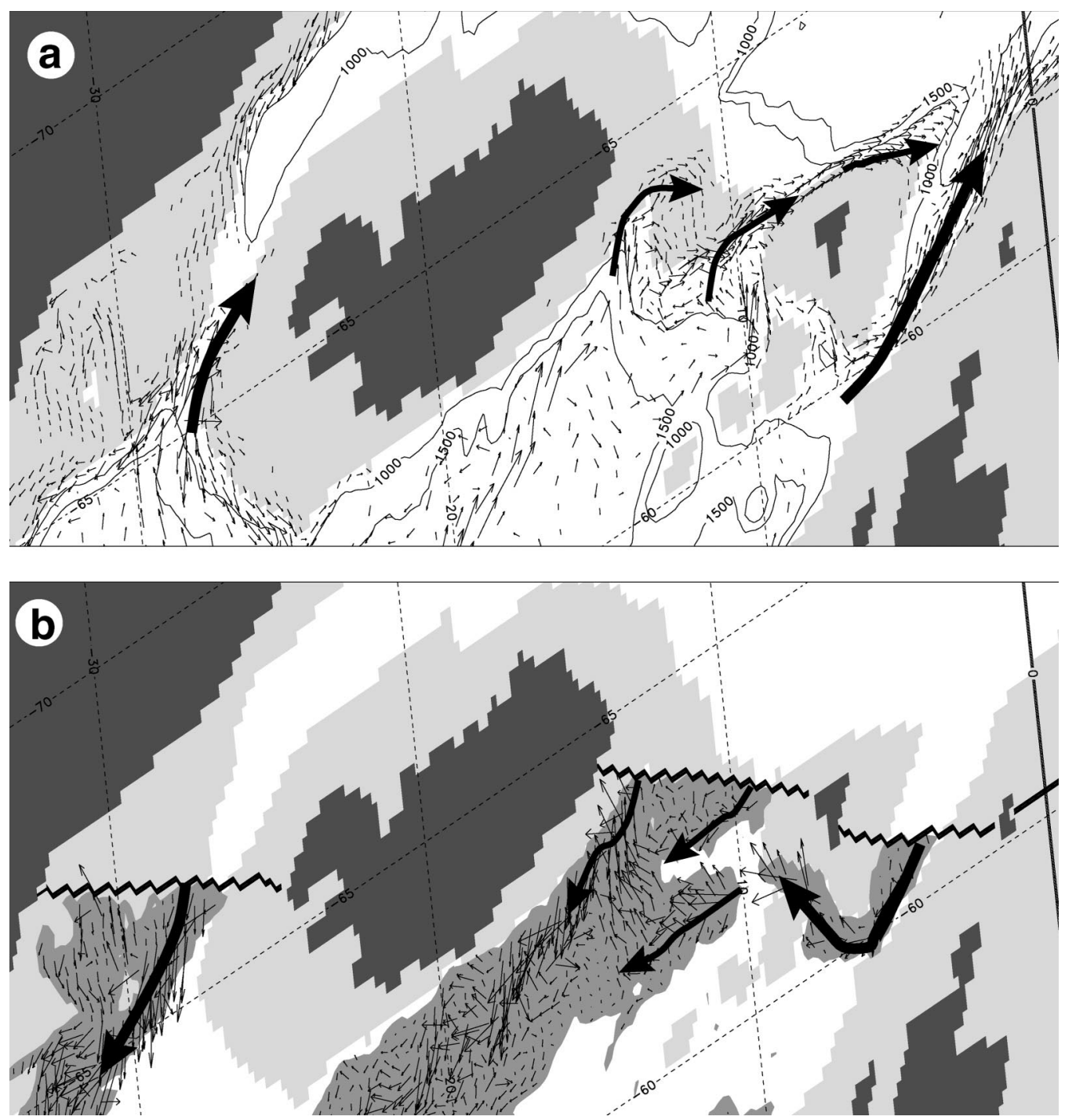

FIG. 2. (a) Vertically integrated transport (in meters squared per second of water $\sigma \leq 27.5$, averaged over months 9-12, in the region of the Greenland-Scotland Ridge (GSR) system in expt WIND. Schematically overlayed are circulation features as indicated by Hansen and Østerhus (2000, their Figs. 5 and 6). In the vicinity of the GSR, every second vector has been drawn in longitudinal direction, elsewhere every fourth (second) in longitudinal (latitudinal) direction. Shaded by light gray is the topography shallower than $500 \mathrm{~m}$. (b) Bottom velocities in the overflow plume (marked in gray) defined by thicknesses greater than $50 \mathrm{~m}$, in longitudinal direction only every second vector is shown. The initial front is indicated by the black line.

Shetland Current east of the Faeroe Islands. Both branches are well represented in our reference run (expt WIND; Fig. 2a). However, in contrast to the observations, the supply of warm water is mainly from the interior Iceland Basin and not by the NAC since the latter is not part of our model setup. West of Iceland the northward flow is restricted to a region south of the sill, except for a narrow northward band on the west Icelandic shelf break. However, the main portion of the water recirculates along both shelf breaks. The presence of an "East Greenland Current" can also be seen.

The cold water path (Fig. 2b) consists of outflows through the FBC and west of Faeroe Islands. As in Hansen and Østerhus (2000, their Fig. 6) it flows southward along the Reykjanes Ridge and the central Iceland Basin, although the latter is only marginally represented. The path through the Denmark Strait is strongest along the Greenland continental slope but also has a contribution on the shelf.

To demonstrate the ability of the model to capture the basic stratification resulting from the overflow under wind forcing, a section through the Irminger Basin at $64^{\circ} \mathrm{N}$ is shown and contrasted to observations (Fig. 3). Starting from a horizontally uniform stratification (Fig. 

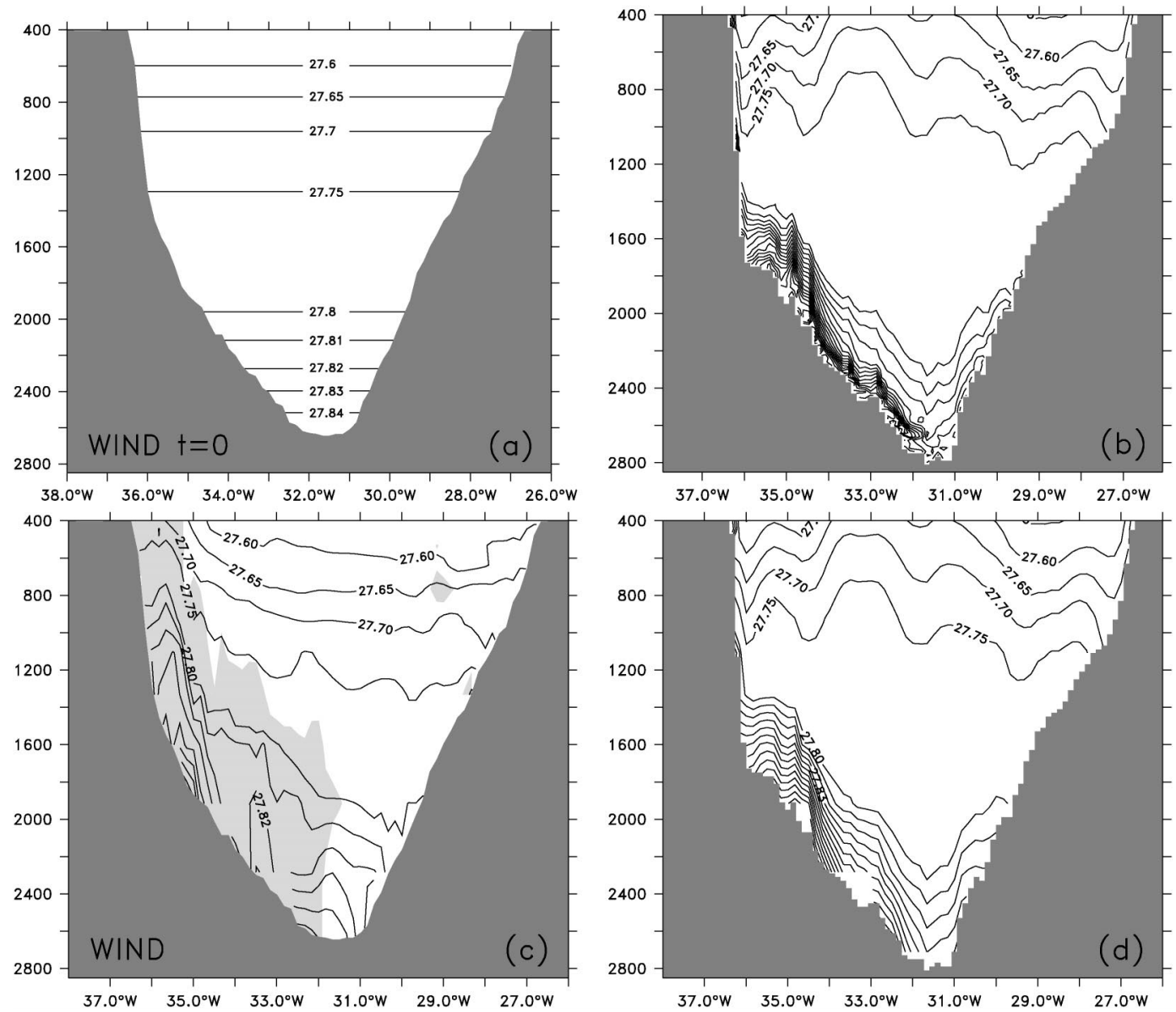

FIG. 3. Density section (in sigma units) at $64^{\circ} \mathrm{N}$ for expt WIND at (a) $t=0$, (c) averaged over three consecutive snapshots between 9 and 19 Jul (shaded by light gray are GIN Seas tracer concentrations above 0.05.), and objectively mapped from cruises with F/S Poseidon over a similar time range: (b) original vertical resolution and (d) interpolated onto model grid.

3a), it takes only about 200 days to reach a realistic density distribution: the $\sigma=27.8$ isopycnal [usually considered to be the upper boundary of the overflow (Dickson and Brown 1994; Girton et al. 2001)] slopes then upward by more than $1200 \mathrm{~m}$ (Fig. 3c), which is in good agreement with observations (Fig. 3b). The presence of denser bottom water in the observations can be explained to some degree by the coarse vertical model resolution and the absence of a model bottom boundary layer; averaging the observations over model levels reduces the near-bottom model-data discrepancy (Fig. 3d).

Overall the model has, attributed to its finite numerical resolution in the vertical, the ability to reproduce a vertical stratification that is comparable to observations in its basic features. This ability is notable since the initial stratification is a horizontal homogeneous one on both sides of the GSR.

The main difference in the observed density structure is seen at the right side of the section where sloping of the isopycnals represent the northward flowing Irminger Current, which is not present in our idealized model.

\section{b. Sensitivity of volume transport}

The sensitivity of the amount of GIN Seas water overflow to changes in wind forcing can best be illustrated using a vertical integral of the GIN Seas tracer. For all experiments this quantity is displayed in Fig. 4 together with the integrated tracer transport of DSOW and south of Iceland of Iceland-Scotland Overflow Water (ISOW). In the reference run with standard wind forcing, a total volume transport of $4.9 \mathrm{~Sv}\left(1 \mathrm{~Sv} \equiv 10^{6} \mathrm{~m}^{3} \mathrm{~s}^{-1}\right)$ is simulated that is distributed almost equally (up to a $20 \%$ difference) between both sides of Iceland. Without wind forcing (NOWIND) the DSOW is only $1 \mathrm{~Sv}$, that is, only $40 \%$ of the transport of ISOW. In contrast, with enhanced wind forcing $(2 \times$ WIND) the amount of DSOW increases substantially and for $4 \times$ WIND represents almost the entire GIN Seas outflow of $6 \mathrm{~Sv}$. An enhanced DSOW overflow is also expressed by the faster propagation of the outflow plume along the continental slope past Greenland and into the Labrador Sea. The plume reaches Flemish Cap for $4 \times$ WIND in less than 200 days, indicating 

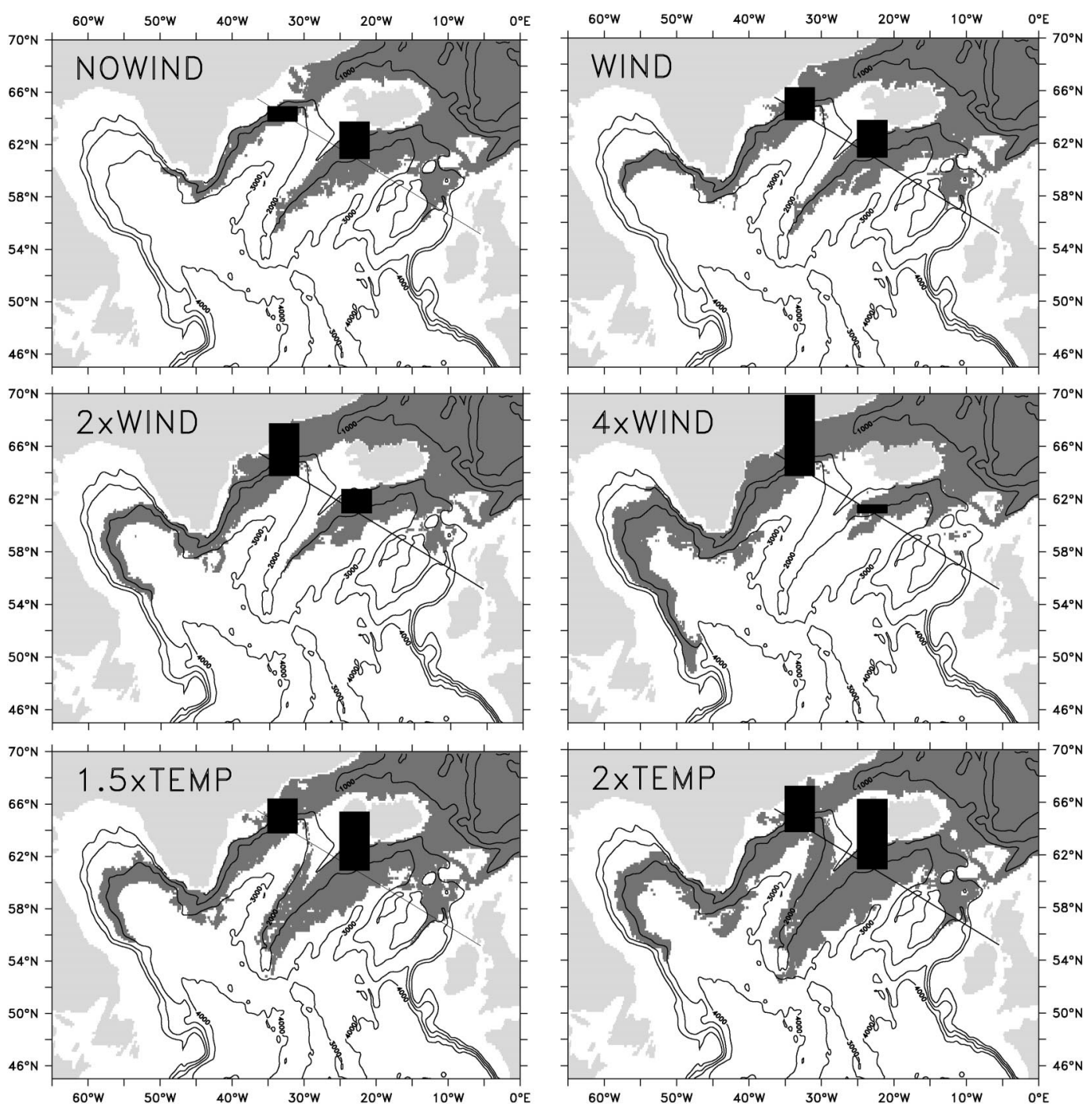

FIG. 4. Overflow plume boundaries after 200 days of integration for idealized experiments. Shown is the vertically integrated GIN Seas tracer with values larger than $25 \mathrm{~m}$. Overlaid is the smoothed bottom topography with contour interval of $1000 \mathrm{~m}$. The black bars show the relative transport of source water through the Denmark Strait and between Iceland and Scotland.

the importance of variations in wind forcing for the communication between the GIN Seas and Labrador Sea. Clearly the strength of the wind forcing is also important for the details of the NADW composition in terms of DSOW, ISOW, and possibly Mediterranean water influence. We note that the rate of change in an individual outflow region changes by a factor of 5 (DSOW) or 6 (ISOW), while the total transport variation compensates partly and is less than a factor of 2 . In other words, a transport increase on one side of Iceland is associated with a decrease on the other side.

While the former experiments describe the influence of the wind forcing in the presence of a climatological density contrast across the ridge, the two further experiments address the role of the density contrast itself on the strength of the outflow and its relative distribution north and south of Iceland. An increase of the density contrast by $50 \%$ or $100 \%$ increases the total throughflow by $40 \%(1.5 \times$ TEMP $)$ and $70 \%(2 \times$ TEMP $)$. Because of the missing hydraulic control in the present model (a too-low plume Froude number), this dependency of the transport differs from a strictly hydraulic control mechanism (e.g., Käse and Oschlies 2000), which would require a linear relationship between transport and density contrast.

To explore the vertical structure of the overflow and the location of the overflow plume relative to the topographic slopes, we show a vertical section of temperature along a section located somewhat south of the GSR from the Greenland shelf through the Irminger Basin across the Reykjanes Ridge into the Iceland Basin to the European shelf as indicated in Fig. 1 (Fig. 5). 

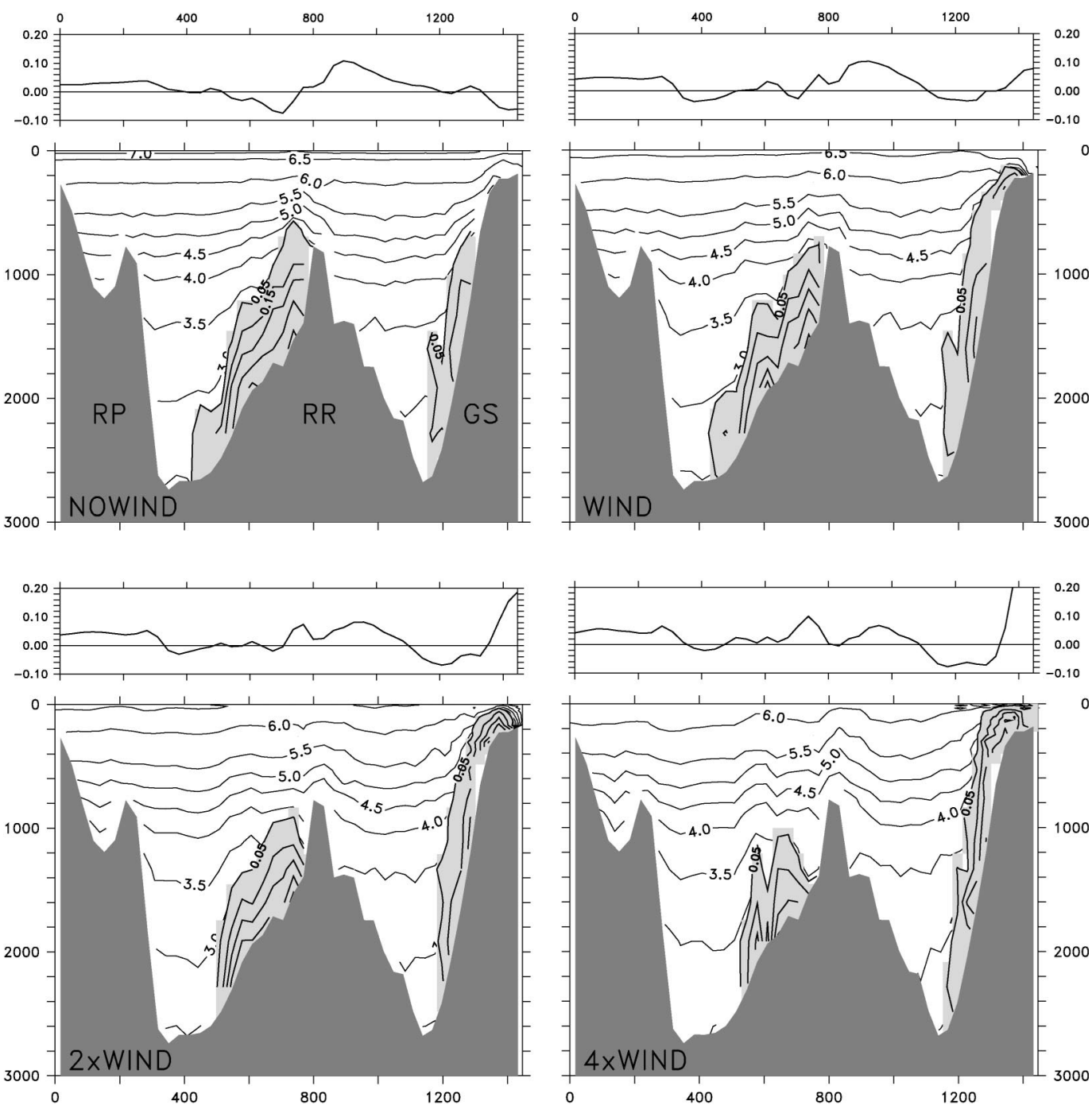

FIG. 5. Temperature field along a vertical section south of the GSR as indicated by the (short) line in Fig. 1 with the section pointing toward northwest at the right side. The field is an average as in Fig. 3c. Superimposed are the concentrations of the GIN Seas tracer. Shown on top of each panel is the sea surface height anomaly along the same section. Labels GS, RR, and RP stand for Greenland shelf, Reykjanes Ridge, and Rockall Plateau, respectively. The section is shown for the wind experiments.

The distribution of the GIN Seas tracer is superimposed for all four wind cases. It follows that the plume of overflow water is mostly located at the right downstream flank of the respective passages. In the left part of the sections, the ISOW plume indicated by $95 \%$ of the diluted GIN Seas tracer spans the whole depth range from $1000 \mathrm{~m}$ to the slope of the Reykjanes Ridge with a maximum thickness of $800 \mathrm{~m}$. The bottom concentration of the GIN Seas tracer reaches up to $50 \%$. With increasing wind, the extent of the plume as well as the bottom concentration is substantially reduced. In contrast, the DSOW plume is significantly enhanced not only in its bottom tracer concentration, but also in its vertical extent. As a result the tracer concentration is dramatically increased over the shelf for increased wind conditions, suggesting that not only the deep passage, but especially the regions over the shallow shelf become of fundamental importance for monitoring an enhanced water mass exchange between the GIN Seas and the subpolar North Atlantic under stronger wind conditions. The necessity of including shelf contributions to the NADW formation has recently been stressed by Rudels et al. (1999) who found a significant flow of Polar Intermediate Water possibly merging with the outflow plume more than $100 \mathrm{~km}$ downstream of the Denmark Strait sill. As will become clear below, this situation is relevant not only for a seasonal cycle in the cross-ridge heat and volume transport, but also for interannual variations, and thus poses stringent constraints on observational designs.

Shown in the figure are also the respective sea surface height $(\mathrm{SSH})$ anomalies along the section. The maxi- 


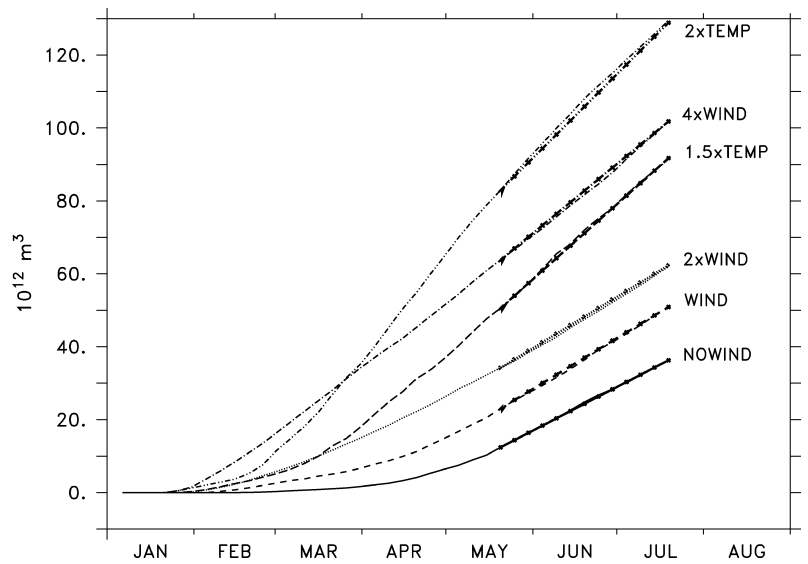

FIG. 6. Total GIN Seas tracer content $\left(10^{12} \mathrm{~m}^{3}\right)$ south of the rotated section (full diagonal line in Fig. 1) as function of time for individual experiments.

mum SSH slope and thus maximum downstream velocity are located near the Greenland shelf for enhanced wind conditions and appear to be related to the DSOW overflow plume. Note also the opposite sense in slope at the other side of the Denmark Strait indicating northeastward flow there. In contrast, for experiment NOWIND, the velocity is strongest south of the Reykjanes Ridge while over the Denmark Strait the flow is generally directed toward the northeast.

The main point that emerges from the sensitivity studies is the shift in southward dense water transport from ISOW to DSOW with increasing wind forcing but an essentially constant sum of both parts. The total overflow can be changed only by altering the cross-ridge density contrast between the two basins. The corollary is that wind changes on seasonal to interannual period do not lead to changes in net volume transports, which have to happen on longer timescales and are related to changes in watermass properties.

\section{c. Tracer and heat transport}

We determined the outflow rate of GIN Seas water from the idealized runs by calculating the time rate of change of the total, vertically and horizontally integrated tracer content in the receiving basin, that is, the subpolar North Atlantic in our model domain. Note that this quantity is independent of entrainment and mixing. The contribution of horizontal tracer diffusion across the section is small, and thus the rate of change south of a given section is equal to the tracer flux across the section itself.

From Fig. 6, which shows the time series of respective tracer content south of the previous section paralleling the GSR, it follows that a constant rate of tracer overflow from all six experiments is reached after about 4 months, and the subsequent steady flow of source water across the section was determined by fitting a line to the last 2 months of the curves. Transports result in 4.6, 5.4, 5.4 , and 7.3 Sv for the four wind cases (from NOWIND

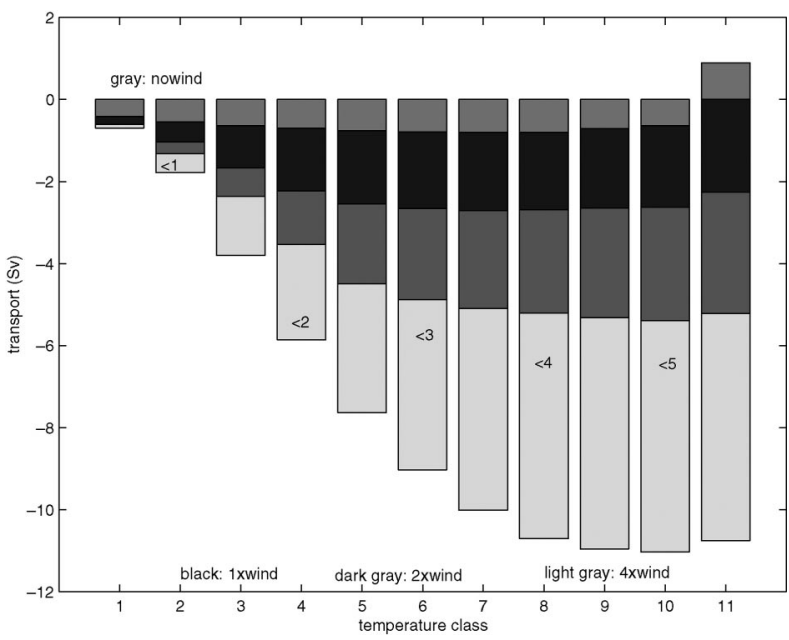

FIG. 7. Histogram of cumulative transport through the Denmark Strait (Sv), split into temperature classes, for the cases NOWIND (gray), WIND (black), $2 \times$ WIND (dark gray), and $4 \times$ WIND (light gray). Shown are mean values over the full range of integration.

to $4 \times$ WIND), respectively. The two cases with enhanced cross-ridge stratification result in $7.9(1.5 \times$ TEMP) and 8.9 Sv $(2 \times$ TEMP $)$, respectively. Note that the two different calculations of source water (Fig. 4 and Fig. 6) differ only because of diffusion across the section.

The outflow of DSOW and ISOW is usually associated with transports below a certain temperature (e.g., Dickson and Brown 1994; Girton et al. 2001). The maximum temperature of the DSOW can be inferred from Fig. 7, which shows the total DSOW transport as a cumulative histogram for temperature classes. Integrating from the coldest water upward is equivalent to integrating from the bottom up and where the respective cumulative numbers reach a stationary value, no further contribution from warmer water masses to the DSOW is obtained. This situation is reached for the standard experiment (WIND) above $2^{\circ} \mathrm{C}$, so that all outflows happen below that temperature. For the extreme case of 4 $\times$ WIND, the outflow water also includes water between $2^{\circ}$ and $4^{\circ} \mathrm{C}$. The increased outflow temperature results from a significant dilution of the source water temperature through Atlantic inflow water. This inflow is especially pronounced in the strong wind forcing case, but ultimately it effects all of our experiments.

The dependence of the Denmark Strait outflow is only marginally affected by the initial cross-basin density stratification but is primarily a function of wind stress curl. Yet, the heat transport across the GSR does show a significant sensitivity to the latter changes (Fig. 8a): For the wind experiments we find a linear relationship between the strength of the gyre (i.e., the strength of the wind forcing) and the heat transport amplitude (the sensitivity is $7.5 \mathrm{TW} \mathrm{Sv}^{-1}$ ). In contrast, the large variations in heat transport for the temperature experiments happen at virtually the same strength of the gyre. 

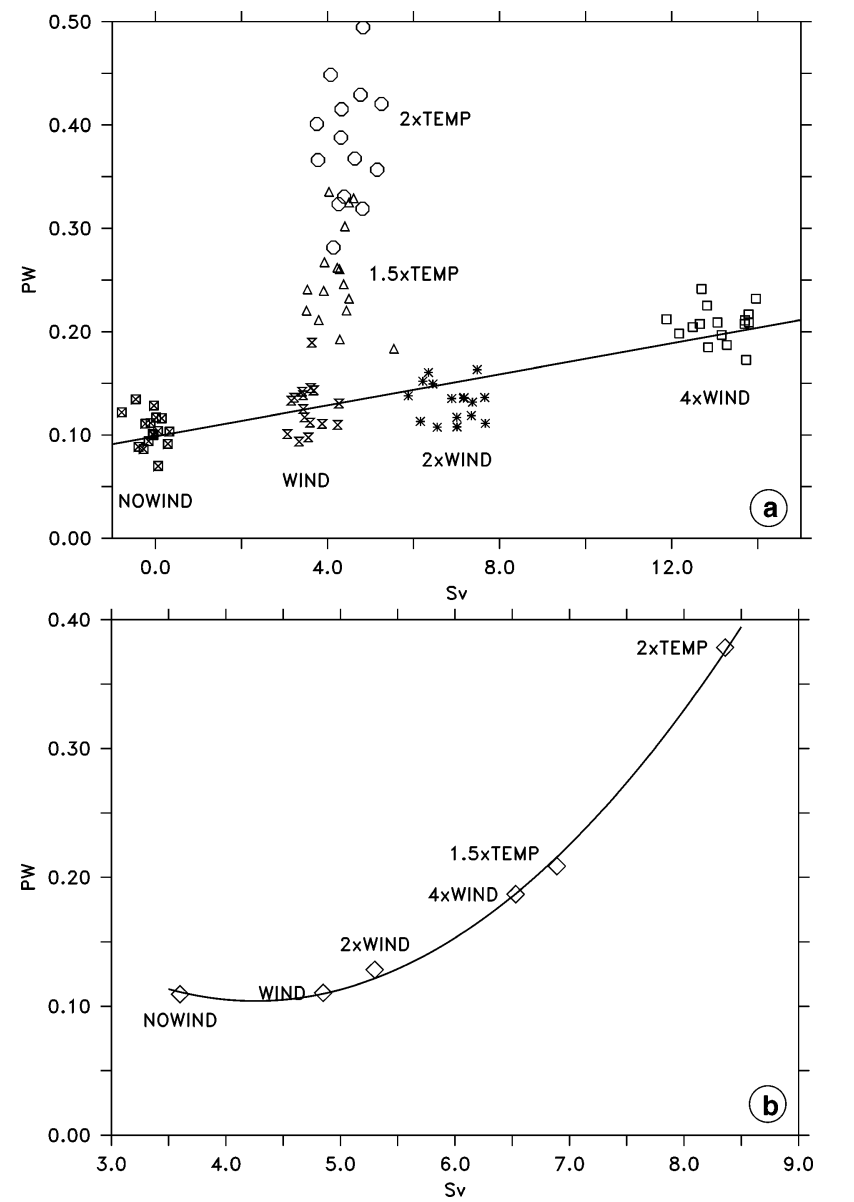

FIG. 8. (a) Heat transport across the sills vs barotropic transport through the Denmark Strait for the different idealized experiments at five daily snapshots in the period 1 May-15 Jul. (b) As in (a) but strength of overturning reduced to $100 \%$ GIN Seas tracer across the section vs heat transport. The individual points represent the averages of the clusters of (a). Shown is also a quadratic fit between the individual points.

The idealized model setup allows one to determine the transport of original source water transport across the sills by analyzing the increase in total tracer volume in the receiving basin. This quantity is independent of downstream mixing processes and determines the total overturning of source water across the ridge system (Fig. $8 b)$. The most striking difference to Fig. $8 \mathrm{a}$ is the collapse of the orthogonal dependencies between the wind and temperature experiments. There is essentially a quadratic dependency of the heat transport to the "source" overturning, resulting in a stronger sensitivity at larger overturning rates. In comparing Fig. 8a and Fig. 8b it follows that the large barotropic circulation changes result in small changes of the overturning strength and the heat transport $\left(7.5 \mathrm{TW} \mathrm{Sv}^{-1}\right)$. In contrast, the heat transport is sensitivity to changes in the overturning across the ridge $\left(47 \mathrm{TW} \mathrm{Sv}^{-1}\right)$. We note that the DYNAMO Experiments (DYNAMO Group 1997) established a relationship between overturning and meridi- onal heat transport at $24^{\circ} \mathrm{N}$ of $50 \mathrm{TW} \mathrm{Sv}^{-1}$ that is similar to our findings. As one reviewer pointed out, the ratio of both is very close to the intuitively expected scaling $\left(T_{S}-T_{B}\right) /\left(T_{E}-T_{W}\right)$, where $T_{S}$ is the surface temperature, $T_{B}$ is the bottom temperature, and $T_{E}$ and $T_{W}$ are depth-averaged temperatures of the ridge system east and west of Iceland, and under the assumption that the ratio of barotropic to overturning transport is of $O(1)$. This ratio is 6.6 as compared with $47 / 7.5=6.3$.

\section{Realistic model simulation}

The previous process studies are interesting in their own right, but they are primarily intended to help in understanding real changes of the subpolar North Atlantic circulation. For that reason the findings of the idealized model runs were tested against a more realistic simulation of the subpolar North Atlantic during the 1990s. The model domain for the realistic run and its horizontal and vertical resolution are identical to the idealized model runs. However, the model was initialized from Levitus December temperature and salinity fields. For the simulation of the surface mixed layer a $k$-profile parameterization (Large et al. 1994) was used. The model was driven by daily wind thermohaline forcing over the 6-yr period 1992-97, which was estimated as part of the ECCO ocean state estimation procedure (for details see Stammer et al. 2002). Because the model domain is still limited by closed boundaries to the north and south and thus excludes the interaction with the large-scale flow field, the integration included a 1-yr spinup period. We also note that a second-order advection scheme was used now in this realistic run for tracers and somewhat higher values for viscosity and diffusion were used (both $25 \times 10^{9} \mathrm{~m}^{4} \mathrm{~s}^{-1}$ at $60^{\circ} \mathrm{N}$ ) than in the idealized runs. However, it was tested in the idealized configuration that these changes do not alter the conclusions described below.

Käse et al. (2001) provided a detailed analysis of the circulation resulting from the realistic model simulation and document that in the Labrador Sea this model is able to simulate the recirculations of the western boundary current regime as it was observed by Lavender et al. (2000) when a partial cell formulation (Adcroft et al. 1997) is being implemented instead of the traditional full cell approach.

In the vicinity of the GSR circulation patterns (Fig. 9) are similar to those obtained in the idealized experiments but the circulation of light water is improved significantly in the Irminger Sea with an improved cyclonic path of the Irminger Current west of the Reykjanes Ridge and an improved East Greenland Current (cf. Fig. 2a). Examining the additional effect of using salinity we compared the development of the full density as compared with the linearized one used for the idealized experiments. For the overflow region both curves are highly correlated but with a reduced variance in the 


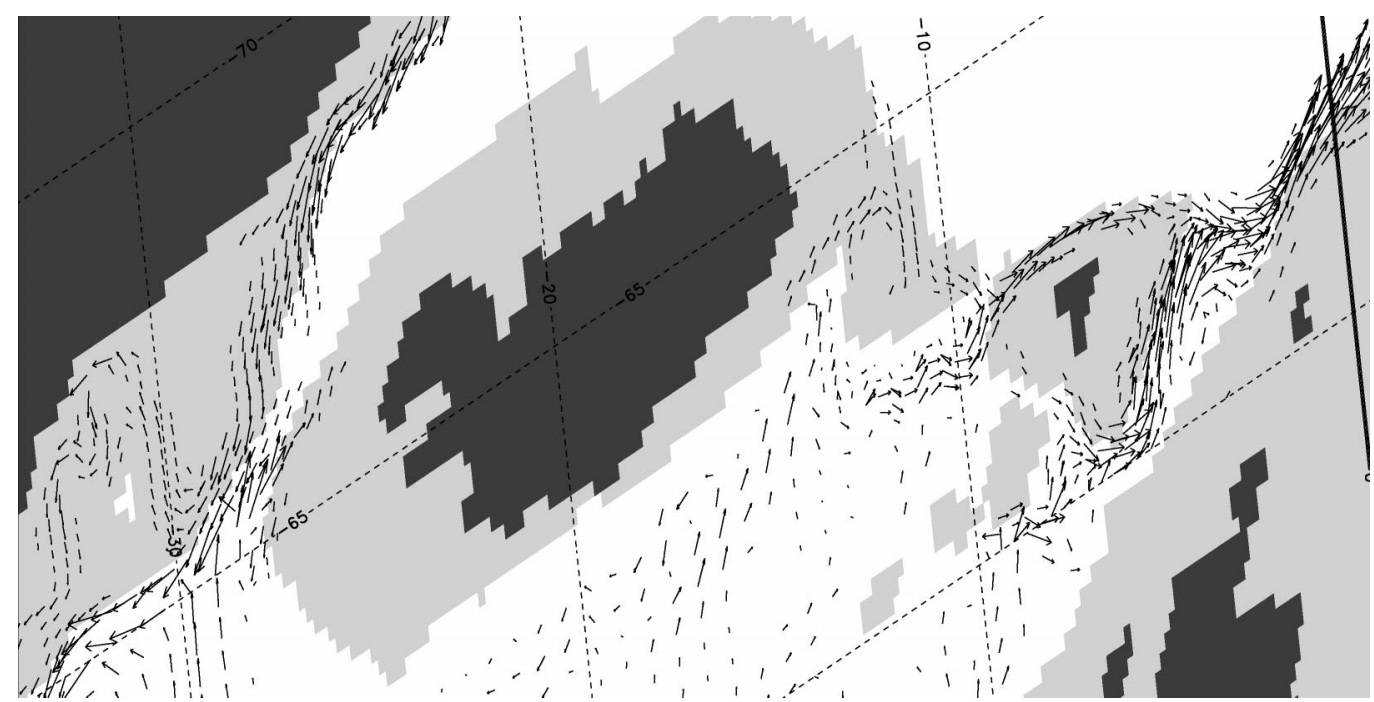

FIG. 9. Warm water transport as in Fig. 2a but mean of year 1992 in the realistic subpolar model.

complete density equation. Therefore, salinity is damping the variability in the realistic model.

A significant limitation of our model setup in simulating realistic conditions is the fact that the closed boundaries prevent the interaction of our model domain with the basinwide circulation. This has consequences for a run with real surface wind and heat fluxes. The ECCO average heat loss over the model domain is 16.7 $\mathrm{W} \mathrm{m}^{-2}$, which under normal conditions is balanced by the horizontal transport divergence in the model domain. However, because the inflow of warm water due to the Gulf Stream/North Atlantic Current is excluded, we cannot reach a stationary model state that is in balance with the realistic surface forcing. Fortunately, the adjustment to the surface heat imbalance is on timescales longer than those of primary interest here. Distributing this heat

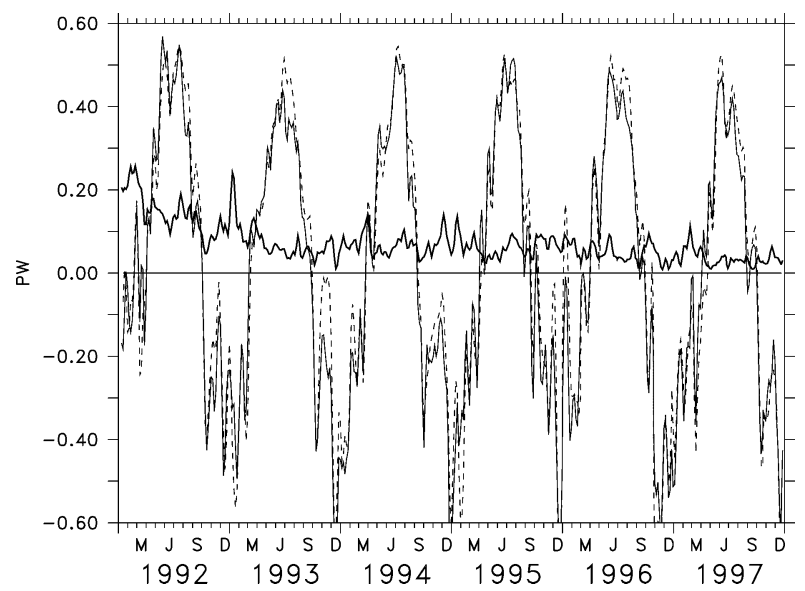

FIG. 10. Heat transport across the GSR system (PW; thick black curve), sum of the former and integrated surface heat flux in the GIN Seas (thin black, positive into the ocean), and rate of heat storage change in the GIN Seas (dashed). loss equally over the whole water column would result

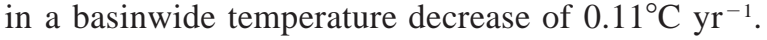

Figure 10 shows the dominant term for the GIN Seas temperature balance-that is, the change in vertically integrated heat storage, the advection across the ridge, and the surface heat flux-over the 6-yr period. The seasonal cycle in the heat storage is typically $0.4 \mathrm{PW}$ and is dominated by the similar signal in the surface heat flux. Note also the variation in heat content changes on a monthly timescale that seem to be highly correlated with local surface forcing. In contrast to the surface forcing, the horizontal heat advection into the GIN Seas across the ridge is about one order of magnitude smaller. It shows a pronounced decrease from about $0.2 \mathrm{PW}$ during 1992 to less than 0.1 PW after 1993. This decrease is associated with the initial adjustment of the system to the surface boundary condition and a related significant decrease in cross-ridge temperature gradient that is equivalent to a transition from the $1.5 \times$ TEMP experiment to the standard run in the previous section. In later years the heat transport still decreases. However, this decrease is then due to variations of the wind field and shows amplitudes of the associated heat flux variations similar to those found from the idealized wind experiments (see Fig. 8a).

To illustrate in more detail the relation between the seasonal variations in horizontal heat flux and changes in the wind stress forcing, we show in Fig. 11 the smoothed barotropic transport through the Denmark Strait together with the wind stress curl maximum in the region $62^{\circ}-70^{\circ} \mathrm{N}, 35^{\circ} \mathrm{W}-5^{\circ} \mathrm{E}$. Also shown are the changes in heat transport across the whole GSR. A lowpass filter was applied to all three time series to focus on seasonal and longer timescales. Quite clearly, all quantities have a pronounced and highly correlated (e.g., $r=0.56$ for heat transport and wind stress) relationship 


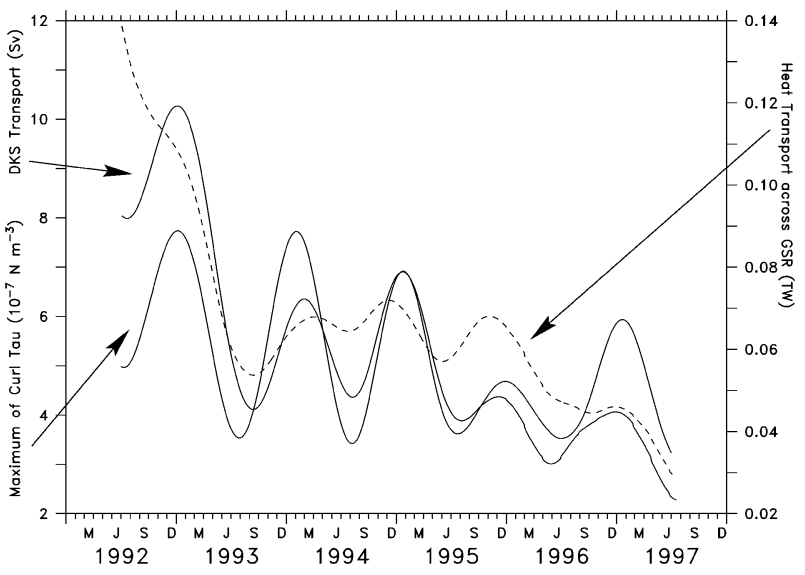

FIG. 11. Barotropic southward transport through the Denmark Strait at $66^{\circ} \mathrm{N}$ (solid thick, Sv) and heat transport across the GSR (dashed, $\mathrm{TW})$. Shown also are maximum wind stress curl in the region $62^{\circ}-$ $70^{\circ} \mathrm{N}, 35^{\circ} \mathrm{W}-5^{\circ} \mathrm{E}$ (solid thin, $10^{-7} \mathrm{~N} \mathrm{~m}^{-3}$ ). All data are smoothed over $1 \mathrm{yr}$.

with most of the correlation resulting from the seasonal cycle with typical amplitudes in barotropic transport changes of about $2 \mathrm{~Sv}$ and $2.2 \times 10^{-7} \mathrm{~N} \mathrm{~m}^{-3}$ in the wind stress curl. As indicated by Fig. 11, an almost exact relation holds for the trend.

Using the results of the idealized experiments we should be able to predict the increase in heat and barotropic transports across the ridge that would result from the observed $40 \%$ variations in wind stress forcing. According to Fig. 8 this would result in an increase in heat transport of $10 \mathrm{TW}$, which is only slightly larger than the heat transport seasonal cycle actually simulated in the realistic experiment $(7.5 \mathrm{TW})$. The seasonal cycle of the barotropic transport predicted from a $40 \%$ wind increase would result in $2.4 \mathrm{~Sv}$.

In summary, both heat and barotropic transports are predicted to be too high by about $25 \%$ in comparison with the realistic experiment, which implies that some additional processes must be involved in their seasonal variations. Yet the wind effect seems to dominate the realistic model transport variability and is of the same order as predicted by the idealized runs.

A pronounced trend is underlying the seasonal cycle in all time series and illustrates the significant decrease of the wind forcing over the subpolar North Atlantic during the 1990s associated with variations in the NAO. From Fig. 11 it can be concluded that the barotropic transport between the subpolar North Atlantic and the GIN Seas decreases simultaneously with the wind stress. Quite strikingly, the heat transport shows the same interannual decrease, indicating that those changes are likely wind induced and in fact could describe changes in the heat exchange across the GSR due to variations of the wind over the GIN Seas on NAO timescales. We note however, that the heat transport trend shows a larger drop in 1992/93, which as discussed before, is related to the initial model adjustments and associated changes

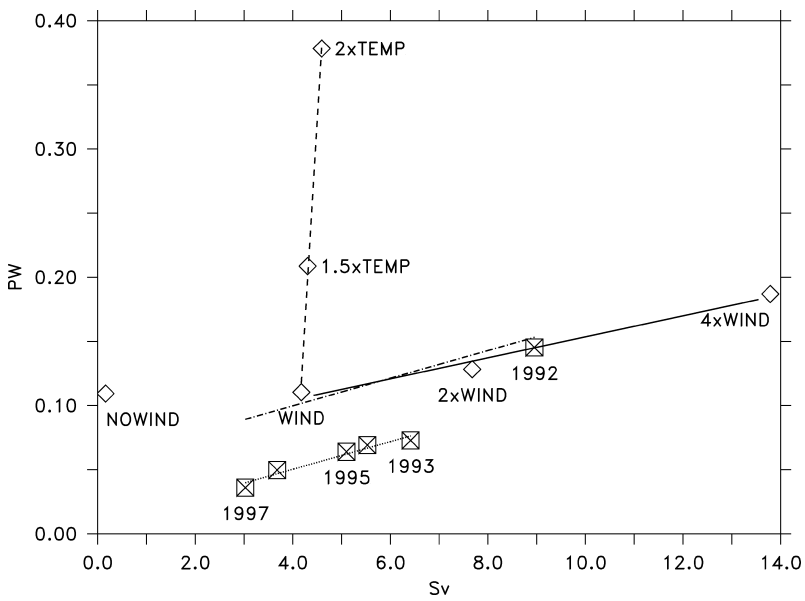

FIG. 12. Heat transport across the sills vs barotropic transport through the Denmark Strait for the different idealized experiments and for the different years of the realistic model. The lines show fits for the wind cases (WIND, $2 \times$ WIND, $4 \times$ WIND, solid line), the temperature cases (WIND, $1.5 \times$ TEMP, $2 \times$ TEMP, dashed) and the years 1993-97 of the realistic experiment (dotted line). The dashdotted line is the fit where years 1993-97 are successively corrected by the reduced temperature contrast between GIN Seas and subpolar North Atlantic according to the idealized temperature experiments.

in the cross-ridge temperature contrast. A similar but smaller decrease in heat transport occurred also in 1996/ 97. Those events could describe effects that we would expect to happen on longer timescales because of changes in buoyancy fluxes over the subpolar oceans and the resulting temperature contrast across the ridge that are not properly represented in our model.

\section{Discussion}

The long-term goal of our work is to understand the sensitivity of transport variations between the subpolar North Atlantic and the GIN Seas to variation in atmospheric forcing over both basins and to simulate and explain the variations that took place over the northern North Atlantic during the 1990s or before. The limiteddomain model setup precludes an interpretation of longterm changes. However, the presence of the idealized model sensitivity runs together with the simulation of the period 1992-97 does provide insight into the mechanisms that dominated the realistic simulation and potentially the real ocean during this 6-yr period.

A summary of all our model runs is presented in Fig. 12. This figure shows the time averages of the barotropic transports together with the cross-ridge heat transport from the idealized experiments and corresponding annual mean values from the realistic model run. Values summarizing the idealized runs are identical to arithmetic means of respective point clusters shown in Fig. $8 \mathrm{a}$. Based on those results, the behavior in the realistic model can be summarized as follows.

With relatively strong wind forcing in the beginning, the model shows a heat transport that corresponds to 
about 2 times a normal condition (i.e., $2 \times$ WIND). Because of initial model adjustment, the interbasin temperature contrast decreases. This leads to a drop in heat transport as it would correspond to a decrease by $30 \%$ from $1.5 \times$ TEMP to normal conditions consistent with a rapid drop in heat transport. At the same time a significant reduction in wind forcing led to a reduction in the barotropic circulation from 9 to $6.5 \mathrm{~Sv}$ between years 1992 and 1993. However, after this adjustment, all subsequent years show heat transport variations that are compatible in their relation to barotropic transport variations with those predicted by the idealized model runs. They correspond to wind changes of $\pm 50 \%$ around normal conditions and show a gradual decrease in barotropic transport from about $6 \mathrm{~Sv}$ in 1993 to $3 \mathrm{~Sv}$ in 1997. Using the results of the idealized model, we have estimated the change in heat transport that is caused by this artificial reduction from the idealized runs and used it subsequently to correct the relation between barotropic transport and heat transport for the years after 1992. The resulting line collapses onto the trend that describes the wind dependence in the idealized model runs over the full 6-yr period 1992-97.

The implications of Figs. 11 and 12 are as interesting as they are encouraging. The former figure shows that the realistic wind changes over the northern North Atlantic are on the order of 1-2 times normal conditions and thus consistent with the range covered by our sensitivity studies as simulated. Moreover, the figure indicates that those changes took place with roughly the same amplitude on annual periods and over several years associated with cycles of the NAO. Figure 12 then shows that the response of the full system is identical to that of the idealized experiments on interannual timescales. Not shown in the figure is the seasonal cycle that would lead to an oscillatory behavior along the regression line from high values in 1992 down to low values in 1997. Accordingly the heat and volume exchange between the North Atlantic and GIN Seas system to observed changes in wind forcing can now be predicted from the idealized runs.

We recall that our model shows a sensitivity to wind changes that is similar to what was found for the DYNAMO model, suggesting that results shown here are generic and not specific to our model setup and resolution. To the extent that we simulate realistic conditions, our results suggest that one ought to be able to predict interbasin exchanges of volume and heat from observed or predicted wind stress changes on seasonal, interannual, or even longer timescales.

One important aspect remains to be discussed: observations suggested no seasonal cycle in DSOW transport (Jónsson 1999), while we do show significant variations in volume and heat transport. This contradiction might be resolved by noting that, while the deep flow field in the Denmark Strait remains unchanged, the shallower part at the shelf break varies and contributes a significant portion to the overflow (Girton et al. 2001).
This fact, which has been overlooked until now, calls for a dedicated observing campaign and might clarify the role of the shallow shelf region off Greenland. First attempts to obtain longer-term measurements in that area are under way within the framework of the German project SFB 460 and comprise current meter measurements with trawl-protected equipment in regions that were formerly unaccessible because of heavy fishery (Macrander et al. 2002).

Acknowledgments. The computational support from the National Center for Atmospheric Research and through an NCAR grant from the National Partnership for Computational Infrastructure (NPACI) is acknowledged. Supported in part through NASA Grant NAG58623 and an ONR (NOPP) Grant N00014-99-1-1049, RHK was additionally supported through the German Research Society (SFB-460). This is a contribution of the Consortium for Estimating the Circulation and Climate of the Ocean (ECCO) funded by the National Oceanographic Partnership Program. We thank the anonymous reviewers for their constructive criticism that helped to improve the manuscript.

\section{REFERENCES}

Adcroft, A., C. Hill, and J. Marshall, 1997: Representation of topography by shaved cells in a height coordinate ocean model. Mon. Wea. Rev., 125, 2293-2315.

Blindheim, J., V. Borovkov, B. Hansen, S.-A. Malmberg, W. R. Turrell, and S. Østerhus, 2000: Upper layer cooling and freshening in the Norwegean Sea in relation to atmospheric forcing. DeepSea Res., 47, 655-680.

Dickson, R. R., and J. Brown, 1994: The production of North Atlantic Deep Water: Sources, rates and pathways. J. Geophys. Res., 99, 12 319-12 341.

DYNAMO Group, 1997: DYNAMO, Dynamics of North Atlantic Models: Simulation and assimilation with high resolution models. Berichte aus dem Institut für Meereskunde Kiel No. 294, $334 \mathrm{pp}$.

Girton, J. B., T. B. Sanford, and R. H. Käse, 2001: Synoptic sections of the Denmark Strait Overflow. Geophys. Res. Lett., 28, 16191622 .

Hansen, B., and S. Østerhus, 2000: North Atlantic-Nordic Seas exchanges. Progress in Oceanography, Vol. 45, Pergamon, 109 208.

_ W. R. Turrell, and S. Østerhus, 2001: Decreasing overflow from the Nordic Seas into the Atlantic Ocean through the Faroe Bank channel since 1950. Nature, 411, 927-930.

Jónsson, S., 1999: The circulation in the northern part of the Denmark Strait and its variability. ICES Tech. Rep. 1999/L, 6, 9 pp.

Käse, R. H., and A. Oschlies, 2000: Flow through Denmark Strait. J. Geophys. Res., 105, 28 527-28 546.

— - A. Biastoch, and D. B. Stammer, 2001: On the mid-depth circulation in the Labrador and Irminger Seas. Geophys. Res. Lett. 28, 3433-3436.

, J. B. Girton, and T. B. Sanford, 2003: Structure and variability of the Denmark Strait Overflow: Model and observations. J. Geophys. Res., 108, 3181, doi:10.1029/2002JC001548.

Large, W. G., J. C. McWillimas, and S. C. Doney, 1994: Oceanic vertical mixing: A review and a model with a nonlocal boundary layer parameterization. Rev. Geophys., 32, 363-403.

Lavender, K. L., R. E. Davis, and W. B. Owens, 2000: Mid-depth recirculation observed on the interior Labrador and Irminger Seas by direct velocity measurements. Nature, 407, 66-69. 
Levitus, S., and T. Boyer, 1994: Temperature. Vol. 4, World Ocean Atlas 1994, NOAA Atlas NESDIS 4, 117 pp.

Macrander, A., R. H. Käse, U. Send, H. Valdimarsson, and S. Jónsson, 2002: Sustained measurements of the Denmark Strait Overflow. Proc. Second Meeting on the Physical Oceanography of Sea Straits, Villefranche, France, ONR, 165-167.

Marshall, J., A. Adcroft, C. Hill, L. Perelman, and C. Heisey, 1997a: A finite-volume, incompressible Navier Stokes model for studies of the ocean on parallel computers. J. Geophys. Res., 102, 57535766.

— C. Hill, L. Perelman, and A. Adcroft, 1997b: Hydrostatic, quasihydrostatic, and nonhydrostatic ocean modeling. J. Geophys. Res., 102, 5733-5752.

Milliff, R. F., and J. Morzel, 2001: The global distribution of the time-averaged wind stress curl from NSCAT. J. Atmos. Sci., 58, $109-131$.

Ross, C. K., 1984: Temperature-salinity characteristics of the "overflow" water in Denmark Strait during "OVERFLOW '73," Rapp. P. V. Reun. Cons. Int. Explor. Mer, 185, 111-119.
Rudels, B., P. Eriksson, H. Grönval, R. Hietala, and J. Launiainen, 1999: Hydrographic observations in Denmark Strait in fall 1997, and their implications for the entrainment into the overflow plume. Geophys. Res. Lett., 26, 1325-1328.

Spall, M. A., and R. S. Pickart, 2003: Wind-driven recirculations and exchange in the Labrador and Irminger Seas. J. Phys. Oceanogr., 33, 1829-1845.

Stammer, D., and Coauthors, 2002: The global ocean circulation during 1992-1997, estimated from ocean observations and a general circulation model. J. Geophys. Res., 107, 3118, doi:10.1029/ 2001JC000888.

_- and Coauthors, 2003: Volume, heat, and freshwater transports of the global ocean circulation 1993-2000, estimated from a general circulation model constrained by World Ocean Circulation Experiment (WOCE) data. J. Geophys. Res., 108, 3007, doi:10.1029/2001JC001115.

Willebrand, J., and Coauthors, 2001: Circulation characteristics in three eddy-permitting models of the North Atlantic. Progress in Oceanography, Vol. 48, Pergamon, 123-161. 